\title{
GNSS Uydu Dağılımının Gerçek Zamanlı Kinematik GNSS ve Ă̆gTK Ölçülerindeki Önemi
}

\author{
İlknur MUTLU ${ }^{1}$, Muzaffer KAHVECi ${ }^{2 *}$ \\ ${ }^{1}$ Konya Teknik Üniversitesi, Mühendislik Fakültesi, Harita Mühendisliği Bölümü, Konya \\ (ilknur.mutlu42@gmail.com) ORCID ID 0000-0001-5289-1915 \\ ${ }^{2}$ Konya Teknik Üniversitesi, Mühendislik Fakültesi, Harita Mühendisliği Bölümü, Konya \\ (mkahveci@ktun.edu.tr) ORCID ID 0000-0001-5380-7164
}

\section{Öz}

A.B.D.nin Global Konum Belirleme Sistemi (GPS) 1980'li yıllarda sivil kullanıma açıldığında tüm sistemin toplam 24 uydudan oluşması öngörülmüş̧ü. Bu öngörü başta haritacılar olmak üzere potansiyel kullanıcılar arasında GPS uydu dağılımının homojen olacağ 1 ve böylece herhangi bir yerdeki gözlemcinin tüm azimut ve yükseklik açılarında sorunsuz olarak uydulara gözlem yapabileceği gibi bir algının oluşmasına neden olmuştu. Ancak, GPS'in sivil kullanıma açılmasıyla birlikte GPS uydu görünürlüğünün coğrafi bölgeye ve özellikle gözlemcinin enlemine bağlı olarak değiştiği ve kuzey enlemlerinde ise yeterli kapsama alanını sağlamadığı görülmüştür. $\mathrm{Bu}$ durum özellikle son 20 yıl içerisinde gerçek zamanlı konum belirleme ve navigasyon uygulamalarında önemli bir sakınca olarak ortaya çıkmıştır.

Zaman içerisinde GPS sistemine alternatif olarak GNSS olarak adlandırılan farklı uydu sistemlerinin (Rusya GLONASS, AB Galileo, Çin Beidou vb.) yaşantımıza girmesiyle ve tüm bu uydu sistemlerinin eşzamanlı kullanımının öngörüldüğü durumlarda bu sorun büyük ölçüde aşılmış gibi görünmektedir. Ancak, her bir uydu sisteminin bağımsız kullanılacağı durumlarda ve gerçek zamanlı klasik kinematik ve ağ-RTK (örn. TUSAGAAktif) ölçüleri söz konusu olduğunda sorunun devam ettiği görülmektedir.

Bu çalışma, Konya Teknik Üniversitesinde devam etmekte olan yükssek lisans tezinin bir bölümünü kapsamakta olup, burada GNSS uydu dağılımının özellikle gerçek zamanlı kinematik GNSS ve A $\breve{g}$ RTK uygulamalarındaki öneminin araştırılması amaç edinilmiştir. $\mathrm{Bu}$ amaç doğrultusunda 2 gün boyunca 7 saat süren statik oturum ve 2 farklı günde A $\breve{g}$-RTK (VRS yöntemi ile) ölçümü yapılmıştır. Noktalara ait uydu görünürlüğü (Skyplot), uydu sayıları ve DOP grafikleri, günümüzdeki uygulamalarda tercih edilen 5 ve 10 derecelik yükseklik açılarında oluşturulmuş ve elde edilen grafikler yorumlanmıştır.

Anahtar Kelimeler: GPS, GNSS, DOP, uydu geometrisi

\footnotetext{
* Sorumlu Yazar
} 


\title{
The Importance of GNSS Satellite Distribution in Real-Time Kinematics GNSS and Network-RTK Measurements
}

\begin{abstract}
When the GPS was begun to be used by the civil community in 1980, it was anticipated that the full constellation would consist of 24 satellites. This plan caused users, particularly geodetic surveyors, think that the deployment of the full GPS constellation would provide a uniform distribution in the sky. In another saying, they thought that the observer anywhere on the Earth 's sky will have a uniform sky distribution which means it would be possible to make observation in all azimuths and elevation angles. But, in real applications it was noticed that GPS sky distribution changes depending on the observer's latitude. And this reality showed that this insufficiency of GPS sky distribution is an important problem particularly for navigational and real time positioning purposes.

On the other hand, in time, as the other satellite positioning systems (GLONASS, Galileo, Beidou, etc.) called as GNSS have appeared this situation seemed to change. When an observer use all these systems simultaneously it can be thought that so-called problem would be eliminated to a great extent. But, if one wants to use any of the GNSS system separately or in real time CORS applications then this problem is said to be still in question in most geographical regions.

This study gives some results obtained via an MSc thesis in Technical University of Konya and it is aimed to investigate the importance of GNSS sky distribution particularly in real time CORS applications.
\end{abstract}

Keywords: GPS, GNSS, DOP, satellite geometry

\section{GíRiş}

Günümüzde GNSS sistemleri yaşantımızın hemen her aşamasında girmiş durumdadır ve temel olarak konum, hiz ve zaman belirleme amaçlarıyla kullanılmaktadır. GNSS' in kullanım alanlarına bakıldığında navigasyon amaçlı kullanımına ilave olarak, jeodezik ve jeodinamik amaçlı hassas konum belirleme ilk sıralarda yer almaktadır. Günümüzde bu amaçlı en yaygın mesleki kullanım gerçek zamanlı sabit istasyonlar ağ (örneğin TUSAGA-Aktif) uygulamalarında görülmektedir.

$\mathrm{Bu}$ kadar yaygın ve önemli kullanım olanaklarına karșın ister statik göreli ister gerçek zamanlı veya mutlak konum belirleme olsun GNSS ölçülerinde de doğruluk kısıtlayıcı hata kaynaklarının olduğu bilinmektedir. $\mathrm{Bu}$ hata kaynaklarından bazılar1; yörünge hataları, atmosferik hatalar, sinyal yansima hataları, uydu geometrisi vb. olarak sayılabilir, (Kahveci ve Y1ldı 2018). Söz konusu hatalar ise doğal olarak nihai amaç olan nokta koordinatlarının doğruluklarını olumsuz yönde etkilemekte ve bu da hataların konum belirlemedeki etkilerinin analizini gerektiren önemli bir husus haline gelmektedir. Bilindiği gibi bu hatalar gözlemci ile uydu arasındaki doğrultunun bir fonksiyonu olarak ifade edilmektedir. Diğer bir ifadeyle, söz konusu hatalar gözlem yapılan uydunun azimut ve yükseklik açısının bir fonksiyonudur. Dolayısıyla, konum belirleme açısından önemli olan En Küçük Karelerle (EKK) dengeleme işlemi yapılırken bu hataların ana amaç olan nokta koordinatlarını nasıl etkilediğinin hesaplanmasıdır (Santerre 1989).

Uyduların birbirlerine ve alıcıya göre olan konumları ve alıcının gördüğü uydu sayısı genel bir ifadeyle uydu geometrisi olarak adlandırılmaktadır. Uydu geometrisi, ölçme öncesi ölçme planı hazırlanırken dikkat edilmesi gereken ve hesaplamalar sonucu elde edilecek doğrulukta payı yüksek olan faktörlerinden biridir. Uydu geometrisinin uygunluğu DOP (Dilution Of Precision: Duyarlılık Kaybı) faktörleri ile ifade edilebilir. DOP faktörleri, uydu geometrisinin navigasyon çözümlerinden elde edilen doğruluklar üzerindeki etkilerini ifade etmekte yaygın olarak kullanılmaktadır. DOP, alıcı ile gözlem yapılan uyduların birbirlerine göre olan göreli konumlarına bağlı olarak tanımlanan ve ölçü noktasına ait konum parametrelerinin "pseudorange" hataları ile ilişkisini kuran doğruluk sınırlayıcı faktörlerdir (Kahveci 2017). Başka bir ifadeyle DOP, GNSS alıcıları ile toplanan verilerin doğruluğuna ilişkin uydu 
geometrisinin gücünü tanımlamak için kullanılan bir terimdir (Babayo ve arkd.,2017; Rita, 2003). DOP değerinin düşük olması uyduların gökyüzüne uygun dağıldığını gösterir. $\mathrm{Bu}$ değer büyüdükçe görülen uyduların uygun dağılımda olmaması durumu yani uyduların birbirine yakınlığı söz konusudur. Yüksek bir DOP, zayıf uydu geometrisini ve daha düşük bir ölçüm uydu konfigürasyonunu gösterir (Opaluwa ve arkd., 2015; Corvallis, 2000). Başka bir ifadeyle görülen uydular ile alıcı arasında çizdiğimiz doğruların oluşturduğu çokgenin alanı ne kadar büyük ise DOP değeri o kadar düşüktür ve konum doğruluğuna etkisi en az seviyededir. DOP kavramının bu yapı ile ifade edilmesi Geometrik DOP olarak adlandırılmaktadır. En uygun uydu geometrisi için ise uydunun birinin alıcının zenit doğrultusunda olduğu ve diğer üçünün bir eşkenar üçgen oluşturduğu tetrahedron yapısı kabul edilmektedir. $\mathrm{Bu}$ geometrik şeklin hacmi ne kadar büyükse uydu geometrisinde ölçüm için en uygun zamandır. Mümkün olan en büyük tetrahedron, bir uydunun zenit doğrultusunda ve üç uydunun gözlemcinin ufuk hattının altında, -19.47 derecelik bir yükseklik açısında olduğu ve eşit azimut aralıklarında bulunduğu geometridir (Şekil 1). $\mathrm{Bu}$ durumda GDOP 1.581 olmaktadır, ancak, dünyanın yüzeyindeki veya yakınındaki bir GPS alıcısının, ufuk altındaki üç uyduyu görmesi pratik olarak olanaklı olmadığından bu senaryo gerçekçi değildir. Bu durumda, mümkün olan en düşük GDOP (1.732), alıcının başucu doğrultusunda bir uydu ve ufukta eșit miktarda yayılmış 3 uydu olarak kabul edilebilir (Langley R.B., 1999).

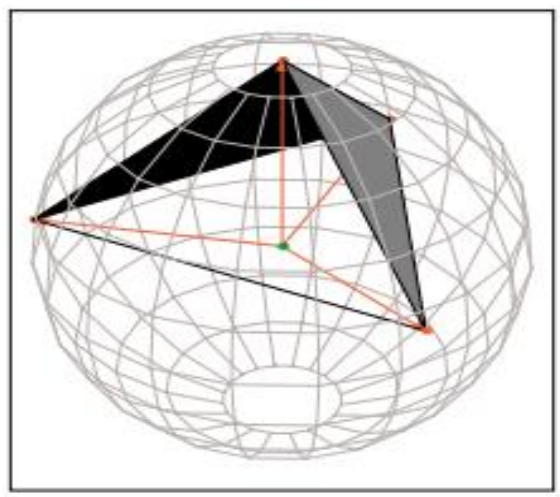

Şekil 1. Tetrahedron (Langley R.B.,
DOP faktörlerini "matematiksel" ve "geometrik" olarak iki farklı şekilde tanımlamak olanaklıdır. Matematiksel DOP, dengeleme sonrası elde edilen kofaktör (veya varyans-kovaryans) matrisinin köşegen elemanlarının fonksiyonu olarak elde edilir. Geometrik DOP ise dört yüzlü üçgen şeklinin hacminin karşılığıdır. Daha yaygın olmasının nedeni; hesaplanmasının kolay olması, matematiksel DOP gibi değişmemesi ve dört uydu gözlemine dayanıyor olmasıdır.

Geometrik DOP'un zayıf yanları aşağıdaki şekilde özetlenebilir:

- Dörtten fazla uydu kullanılamaz.

- Bileşenleri (HDOP ve VDOP) geometrik olarak yorumlanamaz.

- Zenit simetrik uydu takımı için dört yüzlü üçgen şeklinin en yüksek olduğu zaman "matematiksel" PDOP değeri en düşük değer değildir.

- Dört uydu aynı düzlemde olduğunda, dört yüzlü üçgen şeklinin hacmi sıfır (ve 'geometrik' PDOP en yüksek değere ulaşır) olur.

Matematiksel DOP ise yalnızca gözlem noktas1 da bu düzlemde olduğunda en yüksek değere sahip olur (Krauter, 1998).

Uydu geometrisinin hesaplanan nokta koordinatlarına ve saat bilinmeyenine toplam etkisi GDOP (Geometric Dilution Of Precision), yatay ve düşey koordinatlara etkisi PDOP (Position Dilution Of Precision), enlem ve boylama (yatay koordinatlara) etkisi HDOP (Horizontal Dilution Of Precision), nokta yüksekliğine etkisi VDOP (Vertical Dilution Of Precision), zaman bilgisine etkisi TDOP (Time Dilution Of Precision) olarak ifade edilmektedir (Kahveci ve Yıldız, 2018).

$\mathrm{Bu}$ faktörlerden navigasyon çerçevesinde konum doğruluğuna etkisi baz alındığında GDOP ve PDOP değerleri ilgilenilen değerler olacaktır. Diğer faktörlerden HDOP, denizcilikte; VDOP daha çok havacilıkta ve TDOP zaman transfer uygulamalarında kullanılmaktadır. $\mathrm{Bu}$ hesaplanan değerlerin uygulamalarda kabul gören sınır değerleri NATO standartlarına göre Tablo-1'de verilmiştir (Kahveci ve Yıldız, 2018). 
Tablo 1. NATO standartlarına göre DOP faktörleri sınır değerleri

\begin{tabular}{|c|c|c|}
\hline \multirow{3}{*}{ PDOP } & Kullanılabilir & PDOP $<6$ \\
\hline & Sinırda & $\mathrm{PDOP}=6-10$ \\
\hline & Kullanılmamalı & PDOP $>10$ \\
\hline HDOP & Kullanılabilir & $\mathrm{HDOP} \leq 4$ \\
\hline VDOP & Kullanılabilir & $\mathrm{VDOP} \leq 4.5$ \\
\hline TDOP & Kullanılabilir & $\mathrm{TDOP} \leq 2$ \\
\hline
\end{tabular}

Uygulamada bazı GPS alıc1 markaları, almanak bilgisine bağlı olarak mevcut uyduların konumlarını analiz etmekte ve DOP değerinin olabildiğince küçük olmasını sağlamak için bu uyduları en iyi geometriye göre seçmektedirler. Başka bazı GPS alıcı markaları, kullanıcı tanımlı sınırları aşan DOP değerleri ile elde edilen GPS okumalarını yok saymakta ve kullanmamaktadır. Bazı GPS alıcı markaları ise, tüm uyduları gözlem yapabilme yeteneğine sahip olduğu için DOP'u optimum değere indirecek uydu geometrilerini seçerek konumlarını belirlemektedir (Opaluwa ve arkd. 2015).

$\mathrm{Bu}$ çalışmada, GNSS uydu geometrisinin statik ve gerçek zamanlı GNSS ölçülerindeki önemi araştırılmış olup, arazide 3 noktada yapılmış olan statik ve A $\breve{g}$-RTK (VRS: Sanal referans İstasyonu) ölçü ve hesaplamaları ile elde edilen sayısal sonuçlar ve grafikler karşılaştırılmaktadır.

\section{SAYISAL UYGULAMA}

Uydu geometrisinin statik GNSS ölçülerinde ve gerçek zamanlı konum belirlemedeki önemini tespit etmek için 2 gün boyunca 7 saat süren statik oturumlar ve 2 farklı günde Ağ-RTK ölçüsü yapılmıştır. Arazi noktaları Konya Teknik Üniversitesi ve Selçuk Üniversitesi kampüsü çevresinden seçilmiş daha önceden koordinatları bilinen noktalardır. Bu noktalar kampüs içerisinde yer alan KTUN1 (TUTGA), Bosna Hersek mahallesinde yer alan KTUN2 (TUTGA C2) ve KTUN3 (Poligon) noktalarıdır. Noktaların yaklaşık konumları Şekil 2'de verilmiştir.

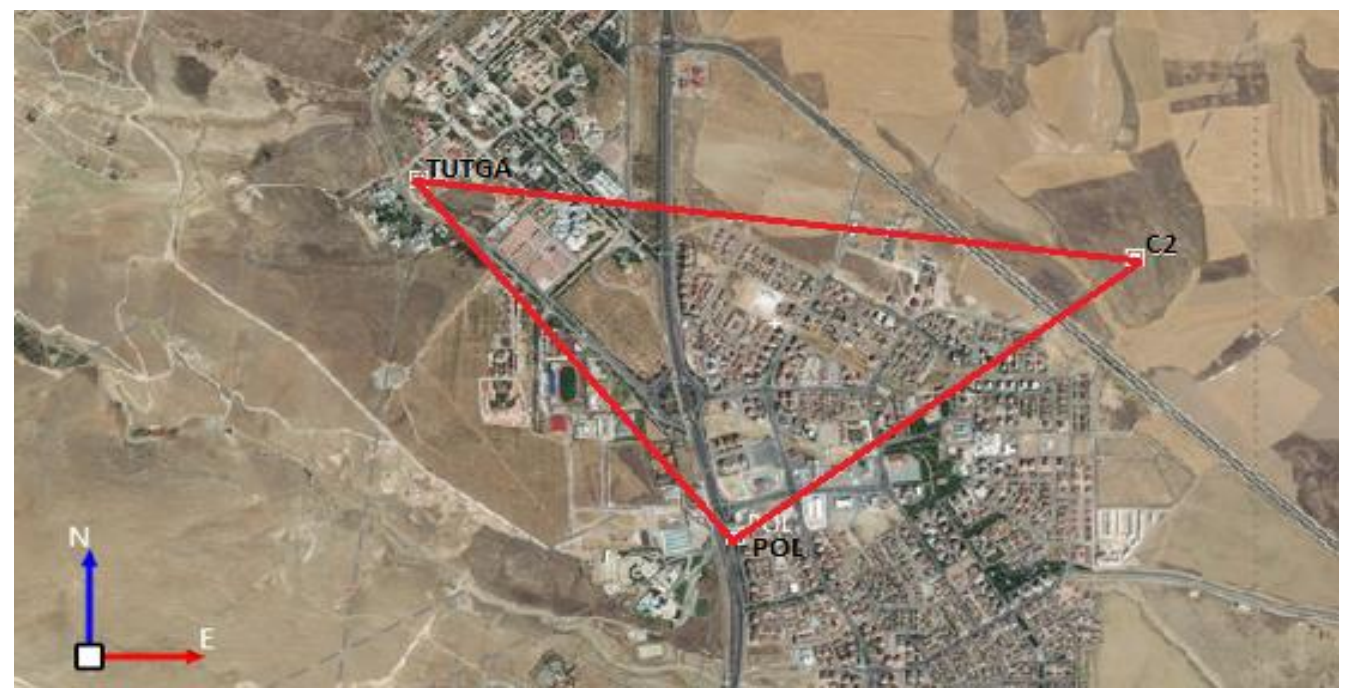

Şekil 2. Noktaların Yaklaşık Konumu (Google Earth ekran görüntüsü)

$\mathrm{Bu}$ noktaların kesin koordinatlarının hesaplanmasinda Konya ilinde yer alan TUSAGA-Aktif noktalarından CIHA (Cihanbeyli), BEYS (Beyşehir) ve KNY1 (Konya) noktaları sabit (referans) nokta olarak alınmıştır. GNSS yazılımında hesaplamaya dahil olan tüm noktaların grafik görünümü Şekil 3'de verilmiştir. 


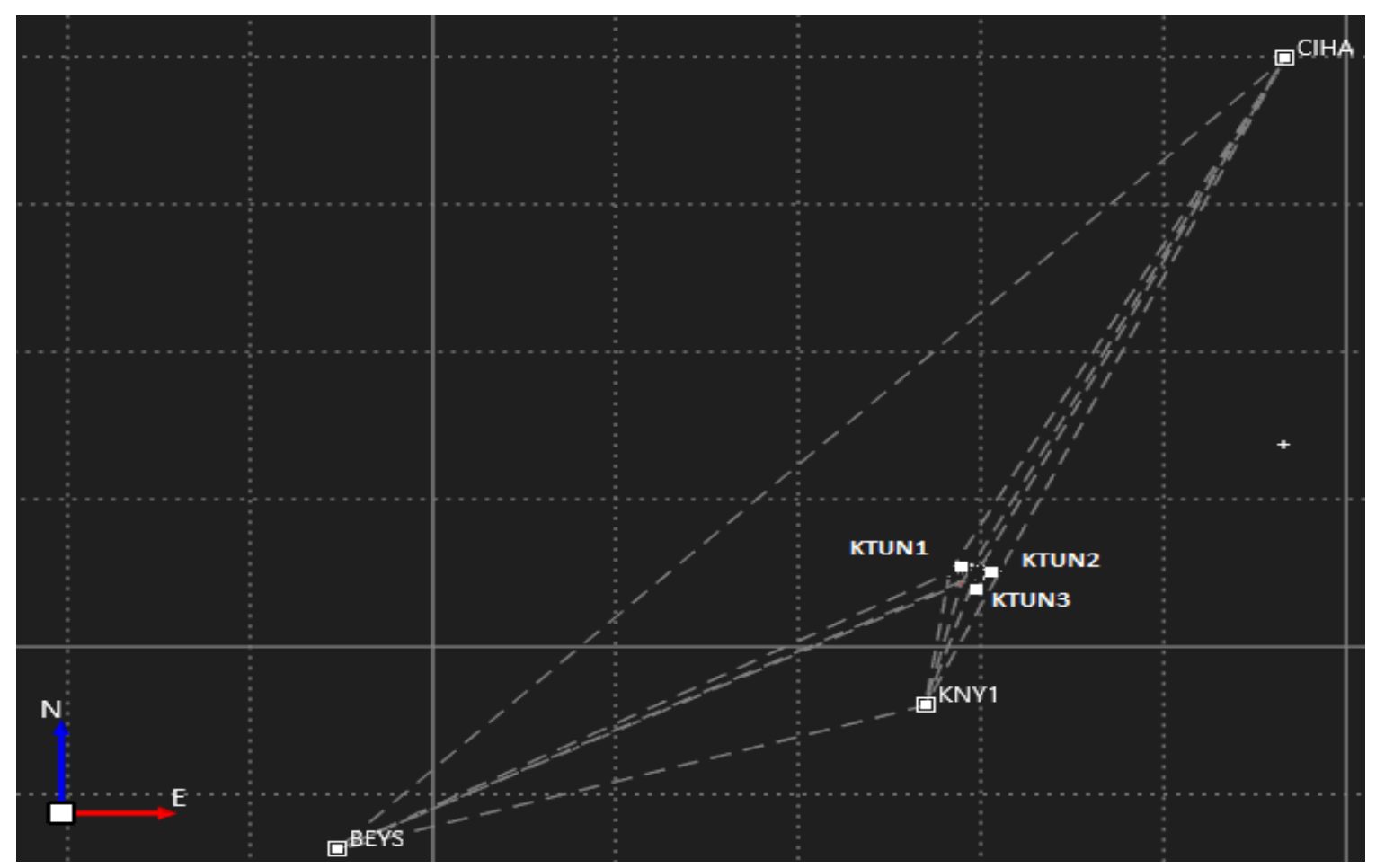

Şekil 3. Hesaplamalarda Oluşturulan Bazlar

4 ve 5 Kasım 2018 günlerinde 09:00-16:00 saatleri arasında statik ölçüler, 6 ve 10 Kasım 2018 günlerinde sirasiyla 10:00-10:30 ve 11:30-12:30 saat aralıklarında A $\breve{g}$-RTK ölçüleri gerçekleştirilmiştir. Statik ölçümlerde TOPCON GR-5 alıcısı, Ağ-RTK ölçüleri için ise TOPCON HiPer SR alıcıları kullanılmıştır.

Arazide elde edilen GNSS verilerinin değerlendirilmesi işlemi için Leica Geo Office yazılımının son sürümü olan Leica İnfinity programı kullanılmıştır. Hesaplamalar, 30 saniye veri aralı̆̆ında ve IGS sonuç yörünge bilgileri kullanılarak yapılmıştır.
KTUN1, KTUN2 ve KTUN3 noktalarına ait 5 ve 10 derece uydu yükseklik açılarında uydu sayıları, DOP grafiği ve uydu görünürlüğü (Skyplot) grafikleri ayrı ayrı elde edilmiş olup, noktalar birbirine yakın mesafede oldukları ve aynı uyduları göreceklerinden, bu grafikler sadece 4 Kasım 2018 ve KTUN2 noktası için Şekil 4'de verilmiştir. Bu şekillerde ölçü noktaları merkez olarak kabul edildiğinde söz konusu yükseklik açılarında gökyüzünde görülebilen tüm uydular yer almaktadır. 


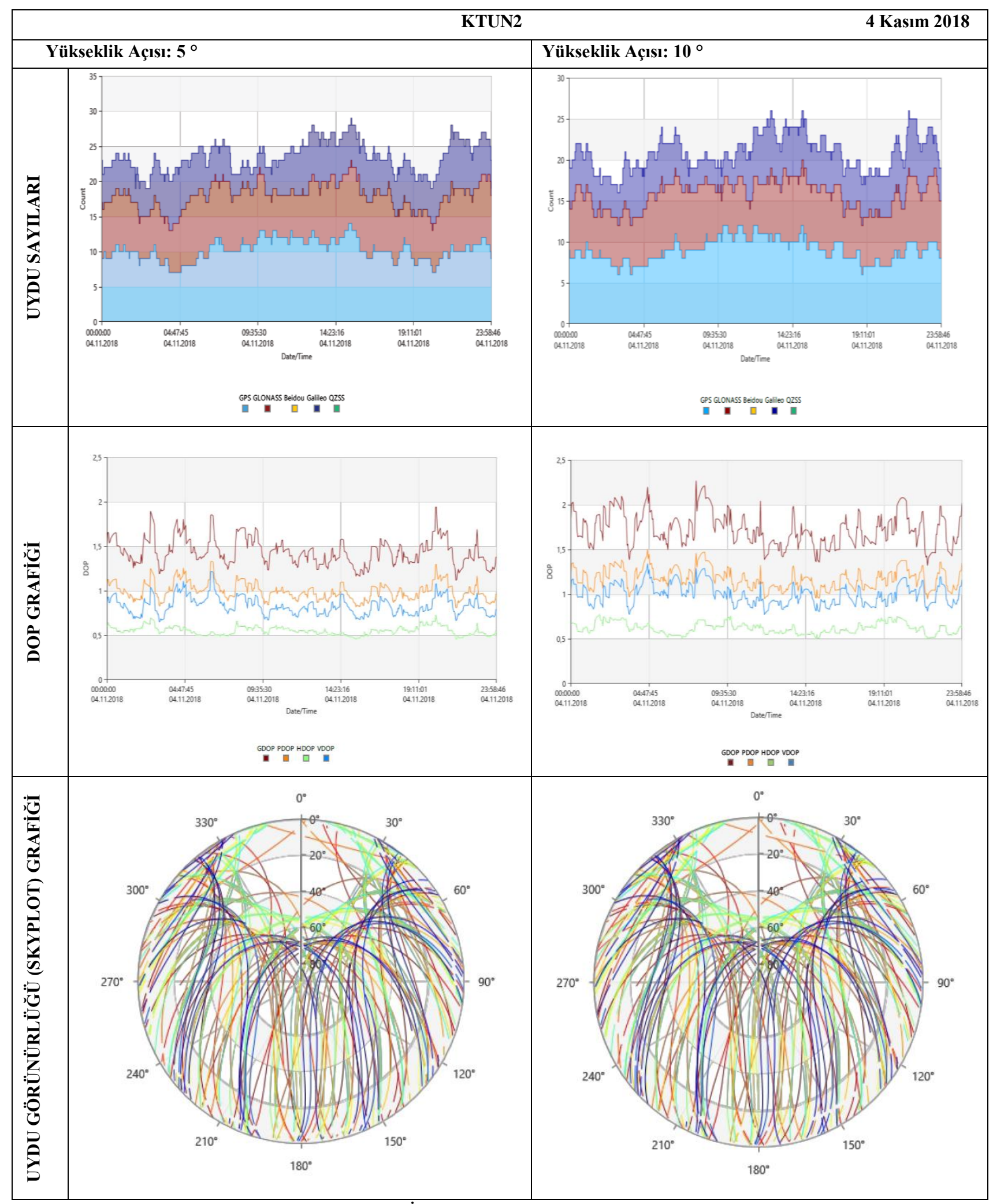

Şekil 4. KTUN2 Noktasında 4 Kasım 2018 İçin Uydu Sayıları ve Görünürlük Grafiği 
Söz konusu uydu grafikleri incelendiğinde, ölçü yapılan noktalarda $5^{\circ}$ için gözlenen uydu sayısının maksimum 30 , ortalama 25 olduğu görülmüştür. Konum belirleme doğruluğunu ifade eden DOP faktörlerinden GDOP maksimum 2, ortalama 1.5 olarak gerçekleşmiştir. PDOP ise ortalama 1.0 olarak elde edilmiştir. $\quad 10^{\circ}$ yükseklik açısında gözlenen uydu sayısının maksimum 26, ortalama 20 olduğu görülmüştür. Buna paralel olarak DOP değerleri yükselmiştir ve maksimum 2.20, ortalama 1.80 olmuştur. Bunlara ek olarak 5 Kasım günü yaklaşık olarak öğlen saatlerinde uydu sayısında oluşan azalma ile DOP değerleri 2.80'e kadar ulaşmışırır. $10^{\circ}$ yükseklik açısında görülen ortalama PDOP değeri ise ortalama 1.30 olmuştur. GNSS ölçüsü yapılan 3 noktanın (KTUN1， KTUN2, KTUN3) aralarındaki mesafenin yaklaşık olarak $2 \mathrm{~km}$ olduğu dikkate alındığında 3 nokta arasında uydu geometrisi açısından önemli bir fark olmadığ belirlenmiștir. Ancak uydu yükseklik açısının artırılmasının görülen uydu sayısında azalmaya neden olduğu ve bunun da DOP değerlerini etkilediği görülmüştür. Tüm grafiklerin ortak özelliği ise GDOP tanımından da anlaşılacağı üzere uydu sayısı ile DOP değerlerinin ters orantı içerisinde olmasıdır. GPS ve GLONASS uydularından veri alan bir alıcı ile yapılan bu sayısal uygulamada uydu sayısının azaldığı durumlarda DOP değerlerinde artış meydana gelmektedir ve bu durum teorik olarak beklenen bir sonuçtur. Bu çalışmada uydu sayısının ve geometrisinin özellikle gerçek zamanlı kinematik ve ağ-RTK konum belirlemeye etkisinin incelenmesi için bazı varsayımlarda bulunularak farklı senaryolar oluşturulmuştur. Bunlardan KTUN2 noktas1 ele alınarak bu noktada 10 derece uydu yükseklik açısında doğu, batı, kuzey ve güney yönlerinde engeller olduğu varsayılmıştır.

Engel çalışması için hesaplamalarda kullanılan Leica Infinity programının uydu gökyüzü grafiği (Sky plot) seçeneği kullanılmıştır. GNSS sistemlerinin her bir uydusunun yer aldığ1 uydu gökyüzü grafiğinden uydu ekleme çıkarma elle yapılmıştır. Böylelikle engel grafikleri için varsayılan engeller doğrultusunda en uygun seçimler oluşturulmuştur.
Hesaplamalar sırasında elle uydu çıkartma işlemlerinde DOP grafiğinin oluşumunda sorunla karşılaşılmıştır. Şekil 5'de KTUN2 noktası ve 10 derece yükseklik açısı için verilen grafiklerde saat 22:20 sonras1 DOP grafiği oluşmamıştır. Bunun nedeni Şekil 5'de görüldügü üzere bu saatte uydu sayısının 3'e düşmüş olmasıdır. $\mathrm{Bu}$ deneyimden de görüleceği gibi günün herhangi bir saatinde alıcının gördügüü uydu sayısının 4'ün altına düşmesi durumunda DOP değerinin hesaplanması olanaksız olmaktadır. Dolayısıyla, ölçü noktasındaki alıcı etrafında uydu görülmesini engelleyen doğal veya yapay engellerin olması durumunda alıcinın nokta konumunu hesaplaması için gereken minimum 4 uydu şartının bile sağlanamayacağı açıktır. Söz konusu senaryolara göre Doğu ve Batı yönlerinde engel olması durumunda uydu görünürlüğü ve DOP grafikleri Şekil 6'da, Kuzey ve Güney yönleri için ise Şekil 7'de verilmiştir.

Şekil 5 irdelendiğinde, uydu sayısının 4'ün altına düşmesi ile aynı zaman aralığı için PDOP değerinin yaklaşı 1800'e, GDOP grafiğinin ise 2500'e kadar çıtı̆̆ 1 görülmektedir. Bu değerler Tablo 1'de verilen sınır değerlerle karşılaştırıldığında sadece birkaç epokluk ölçü yapılarak koordinat belirlenen gerçek zamanlı kinematik uygulamalarda konunun önemi daha da iyi anlaşılmaktadır.

Şekil 6 ve 7 irdelendiğinde şu sonuca ulaşmak olanaklıdır; eğer zorunlu olarak ölçü yapılacak noktanın etrafinda engel varsa ve sadece bir kaç epokluk ölçü ile nokta koordinatları belirlenecekse, bu durumda optimum ölçü zamanının belirlenmesi için bu çalışmaya benzer senaryoların yapılarak karar verilmesinde yarar olacağı sonucuna var1labilir.

Tüm bu grafiklerden de görüleceği gibi, DOP değerleri, ölçü yapılan nokta etrafında hiç engel olmaması durumuna göre ideal değerlere ulaşmaktadır. Bunun anlamı ise alıcı etrafinda alıcının uyduları görmesini engelleyen doğal ve yapay engellerin olması durumunda gözlem yapılan uydu sayısının ve dolayısıyla DOP faktörlerinin olumsuz olarak etkilendiği ve konum belirleme sonuçlarında önemli ölçüde kötüleştirmelere neden olduğudur. 


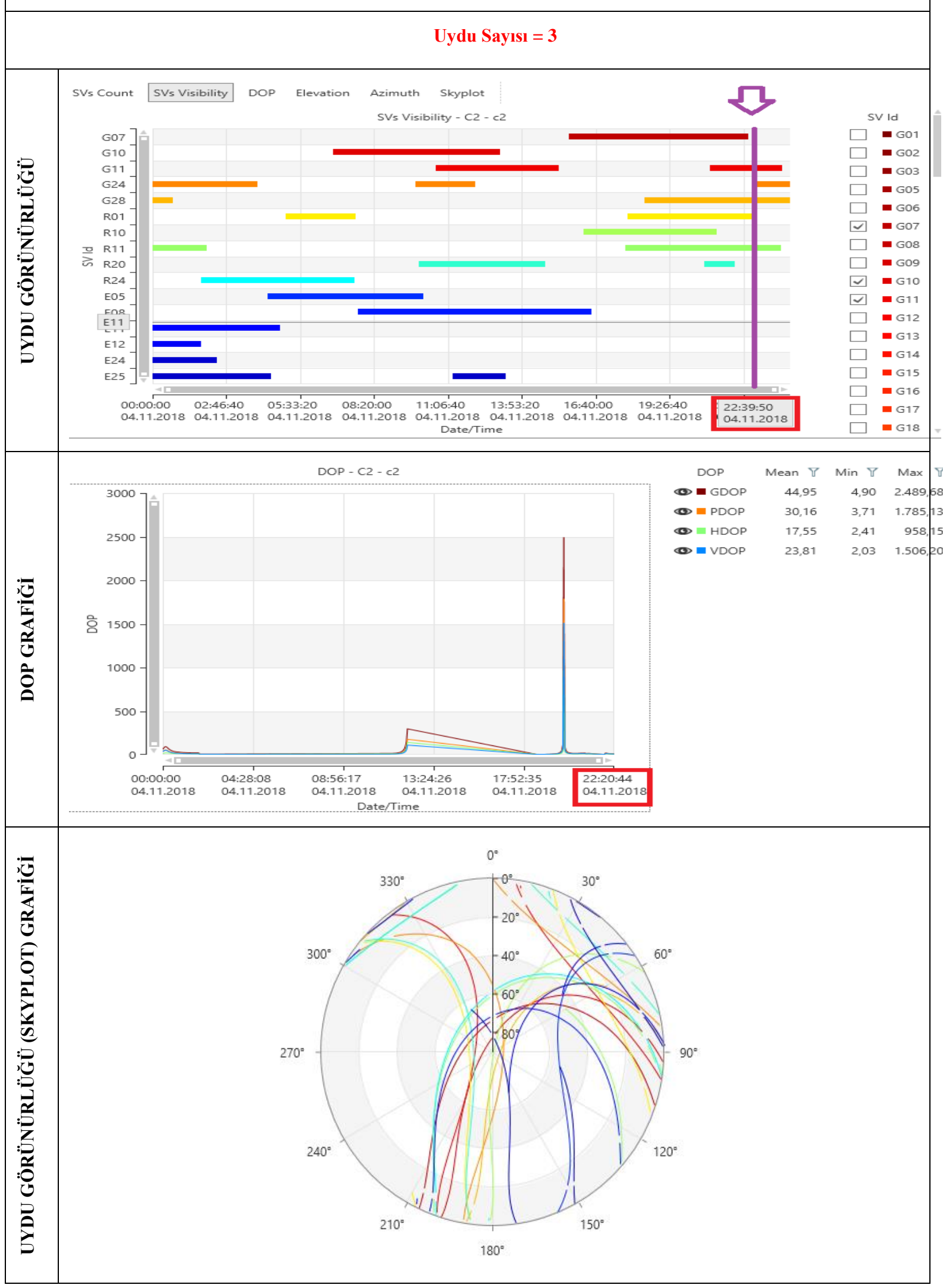

Şekil 5. KTUN2 Noktasında Yetersiz Uydu Sayısının Etkisi 


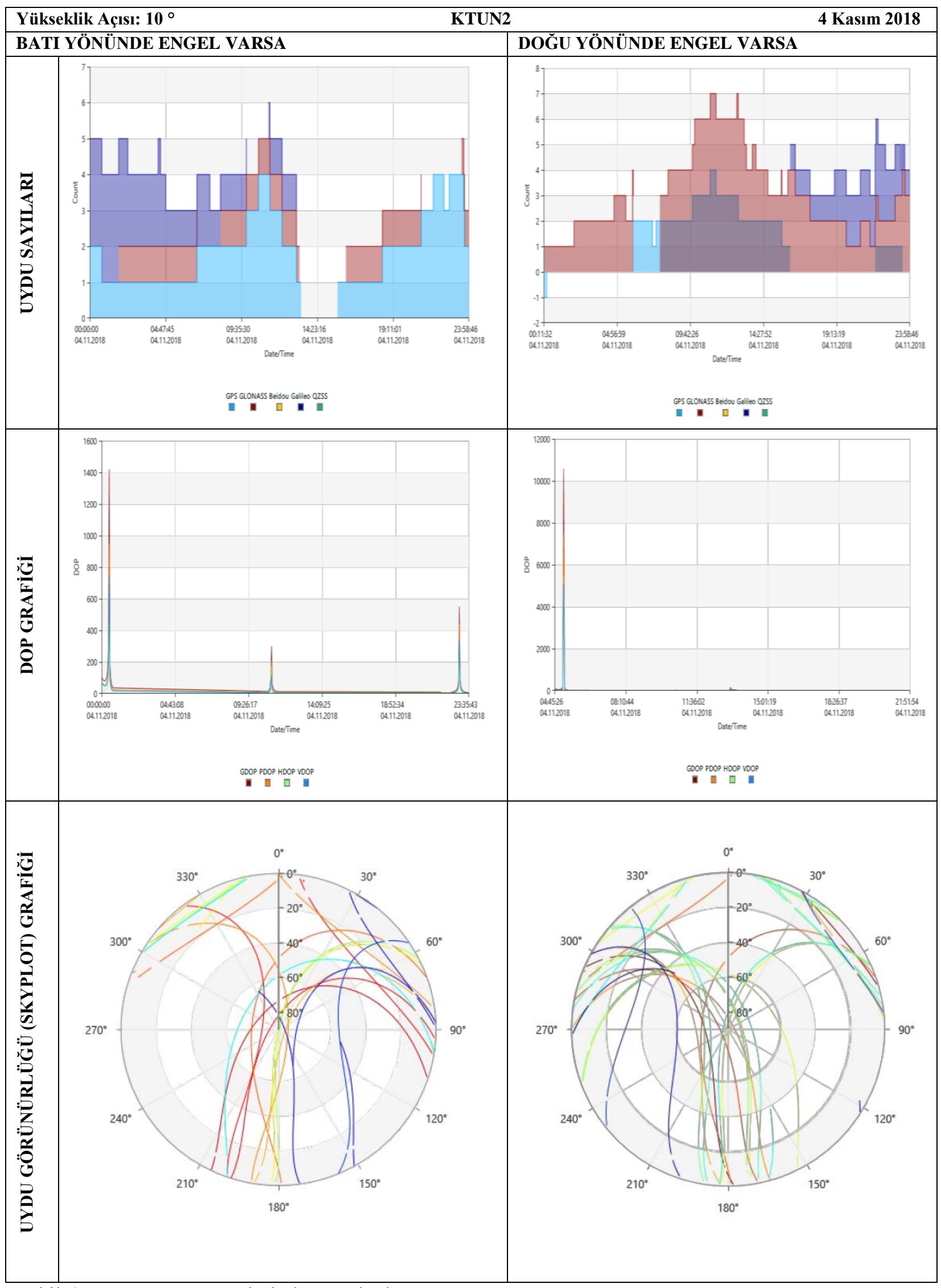

Şekil 6. Doğu ve Batı Yönlerinde Engel Olması Durrumu 


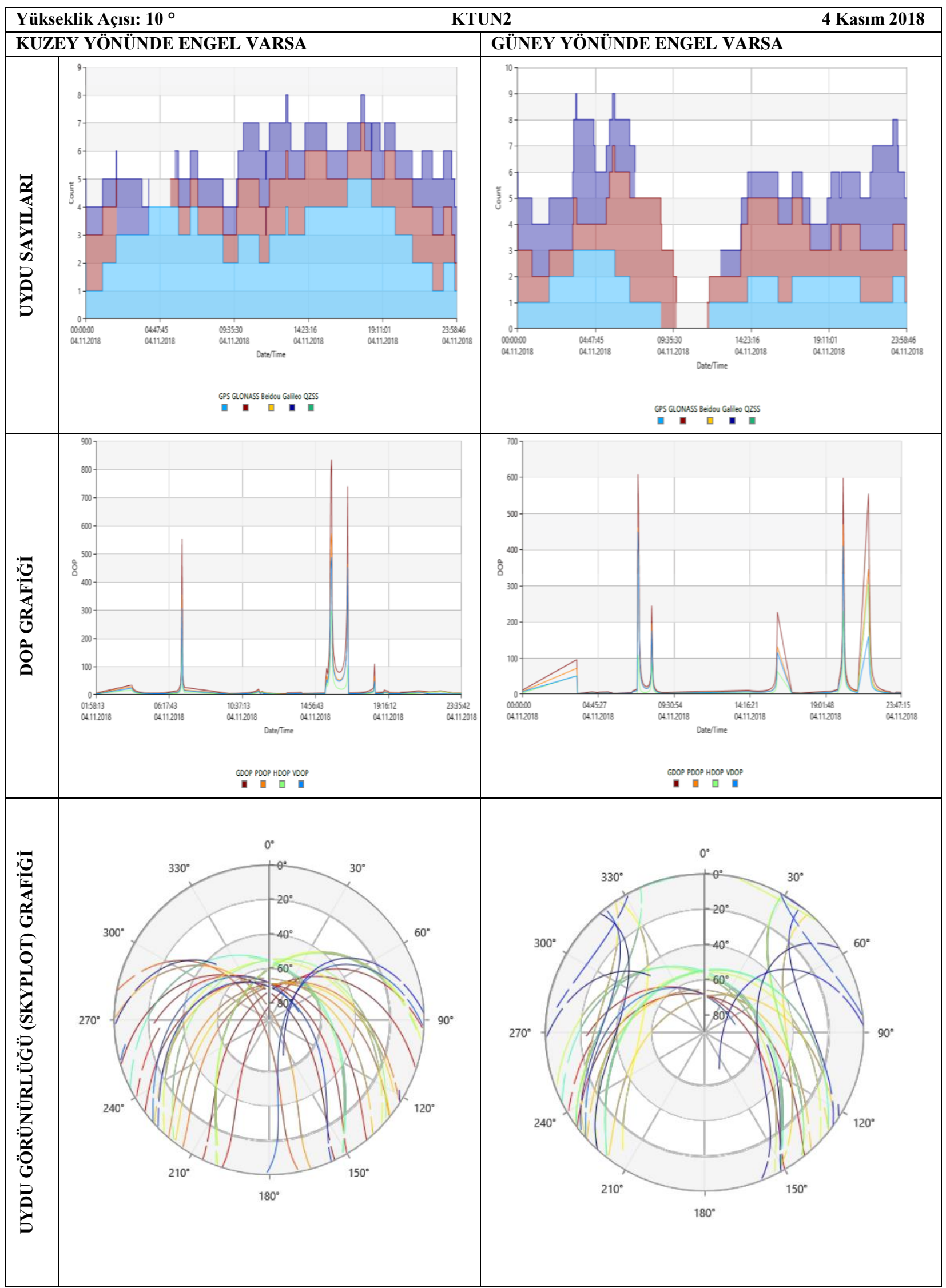

Şekil 7. Kuzey ve Güney Yönlerinde Engel Olması Durumu 


\section{SONUÇ ve ÖNERILLER}

$\mathrm{Bu}$ çalışma, uydu görünürlük grafiklerinin araziye çıkılmadan önce gerek statik gerekse gerçek zamanlı kinematik (A $\breve{g}$-RTK dahil) ölçü planlarının tasarımında ne kadar etkili ve önemli olduğunu ortaya koymak amaciyla gerçekleştirilmiştir. Dolayısıyla, ölçü yapılmak üzere seçilecek veya tesis edilecek noktaların çevresinde öncelikle engel olup olmadığ konusunun belirlenmesi ve bu bağlamda her ölçü noktası için engel grafiklerinin hazırlanması, özellikle ölçü planlamasında söz konusu noktalarda hangi zaman aralıklarının ölçüler için daha uygun olacağı önceden belirlenmelidir. Böylece, zaman ve emek kayb1 önlenerek optimum ölçü planı gerçekleștirilmiș olacaktır. Söz konusu engel grafikleri ile ilgili ayrıntılı bilgi (Kahveci ve Yıldız 2018)'de verilmektedir. Bu konu, günümüzde özellikle birkaç epokluk ölçü ile kurumların arşivine kabul edilen gerçek zamanlı kinematik GNSS ile konum belirlemede çok önemli ve göz önünde tutulması gereken bir husustur. Mevcut GNSS uydu sistemlerinden günümüzde tam kapasite ile hizmet verenlerin (GPS ve GLONASS) datum, zaman sistemleri, sinyal polarizasyonu, vb. teknik detaylarda farklılıklarının da ölçü sonrası elde edilecek sonuç koordinatlarının doğruluklarını etkileyen faktörler olduğu göz önünde tutulduğunda konunun önemi daha da artmaktadır.

Çalışma kapsamında çok sayıda senaryo denenmiş ve hesaplanmış olmakla birlikte bu makalede örnek olarak sadece KTUN2 noktasına ait sonuçlar paylaşılmıştır. Elde edilmiş olan sonuçlar irdelendiğinde, statik (en az 1 saat ve daha uzun) GNSS ölçü ve hesaplamalarında uydu geometrisi sürekli değiştiği ve her durumda çok sayıda uydu gözlenebildiği için ölçü noktası etrafındaki uydu sinyalini engelleyici doğal veya yapay engellerin olması, bu engellerin 5 derecenin altında kaldığ 1 ve noktadan belirli bir uzaklıkta olduğu sürece önemli olmadığ 1 söylenebilir. Ancak, ölçü noktası yakın civarındaki yüksek gerilim hatları ve manyetik alanlar çok farklı bir hata kaynağı oluşturdukları için ulaşılan bu sonuçların dışında ayrı bir çalışma ve yorum konusudur.

$\mathrm{Bu}$ bağlamda ulaşılabilecek en önemli sonuç ise, gerçek zamanlı kinematik GNSS ile konum belirlemede bir kaç epokluk ölçümlerin istatistik olarak çok riskli olduğu, ölçü süresi ne kadar uzun olursa o kadar tutarlı ve güvenilir sonuçlar elde edileceği çıkarımıdır. Dolayısıyla, bir kaç epokluk kinematik GNSS ölçümleri ile jeodezik ve kadastro amaçlı konum belirlemelere ilişkin mevzuatın bu çalışmadaki sonuçlar göz önünde tutularak güncellenmesinde yarar olduğu değerlendirilmektedir.

\section{KAYNAKÇA}

Babayyo A., Abubakar T., Umar S. (2017). Time Optimization for GPS Observation using GNSS Planning, Department of Surveying and Geoinformatics Federal Polytechnic Bauchi, Nigeria.

Corvallis. (2000). Introduction to Global Positioning System for GIS and Traverse. Corvallis, USA: Corvallis Microtechnology, Inc. 413 S.W Jefferson Avenue..

Kahveci M., (2017). Kinematik GNSS ve RTK Cors Ağları, 2. Basım, Nobel Yayıncılık, Ankara.

Kahveci M., Yıldız F., (2018). GPS/GNSS Uydularla Konum Belirleme Sistemleri, 10.basım, Nobel Yayınc1lık, Ankara

Krauter A., (1998). Role Of The Geometry In Gps Positioning, Department of Surveying Technical University of Budapest, 1998, Budapest, Hungary.

Langey R.B., (1999). Dilution of Precision, GPSWORLD, may1999, University of New Brunswick

Opaluwa Y., Abazu C. I., Okorocha C. V., Odumosu J., (2015). The Effect Of Gps Satellite Geometry On The Precision Of Dgps Positioning In Minna, Nigeria, Jurnal , Teknologi, Department of Surveying \& Geoinformatics, Federal University of Technology Minna, Nigeria

Rita, D., (2003). Civil Gps service interferance, United State: Us Department Of Homeland Security, Coastland Navigation Center.

Santerre, R. (1989). GPS Satellite Sky Distribution: Impact on the Propagation of Some Important Errors in Precise Relative Positioning. Ph.D. dissertation, Department of Surveying Engineering Technical Report No. 145, University of New Brunswick, Fredericton, New Brunswick, Canada, pp. 220. 